\title{
Alterações químicas e físico-químicas em grãos de abóbora durante 0 armazenamento ${ }^{1}$
}

\author{
Tailândia M. C. Belmiro², Alexandre J. de M. Q ueiroz², Rossana M. F. de Figueirêdo², Tâmila K. S. Fernandes² \& Maria da C. T. Bezerra ${ }^{2}$
}

\section{RESU MO}

Realizou-se este trabalho com o objetivo de verificar as alterações químicas e físico-químicas em grãos de abóbora secados durante 0 armazenamento convencional (temperatura ambiente), visando avaliar a qualidade do produto em relação às características qualitativas iniciais. 0 s grãos de abóbora foram submetidos a secagem em estufa a $100{ }^{\circ} \mathrm{C}$ com o intuito de se produzir amostras secadas com 2, 4, 6, 8 e 10\% de teor de água; $T_{1}, T_{2}, T_{3}, T_{4}$ e $T_{5}$, respectivamente. As amostras, já secas, foram armazenadas em embalagem rígida de polipropileno, com tampa, durante 180 dias, a temperatura ambiente. A cada 30 dias os grãos secos foram submetidos a análises química e físico-química, ao longo do armazenamento, determinando-se o teor de água, cinzas, pH, acidez total titulável, proteína bruta, amido, fibra bruta e cor. Verificou-se que não houve alteração do teor de água nos tratamentos $\mathrm{T}_{1}$ e $\mathrm{T}_{5}$ (teor de água iniciais 2 e $10 \%$, respectivamente). 0 correu aumento de acidez entre o início e o final do armazenamento para todos os tratamentos, e redução do pH, para quatro dos cinco tratamentos mas houve manutenção da proteína bruta, da fibra bruta, do amido, das cinzas, da luminosidade, da intensidade de vermelho e da intensidade de amarelo, indicando que os grãos de abóbora se mantiveram em boas condições durante o período avaliado.

Palavras-chave: Cucurbita moschata, resíduos agrícolas, propriedades nutricionais

\section{Chemical and physico chemical changes in pumpkin grains in storage}

\begin{abstract}
This w ork aimed to verify chemical and physico-chemical changes in dried pumpkin grains, during the standard storage (room temperature), to evaluate the maintaining of initial qualitative characteristics. Drying of the grains took place in an oven at $100{ }^{\circ} \mathrm{C}$ until the moisture content reached $2,4,6,8$ and $10 \%$, at $T_{1}, T_{2}, T_{3}, T_{4}$ and $T_{5}$, respectively. D ried samples were stored in rigid polypropylene packing, with cover, for 180 days, at room temperature. Every 30 days, dried grains were submitted to chemical and physico-chemical analyses: moisture content, ashes, pH, total titrable acidity, crude protein, starch, crude fiber, and color. It was checked that there was not any alteration in moisture content for the treatments $\mathrm{T}_{1}$ and $\mathrm{T}_{5}$ (2 and 10\% initial moisture content, respectively). Crude protein, crude fiber, starch, ashes, brightness, redness and yellowness remained constant. Increasing of acidity were observed in the beginning and at the end of the storage, for all treatments, as well as a reduction in $\mathrm{pH}$ for four of the five treatments.
\end{abstract}

Key words: Cucurbita moschata, agricultural residue, nutritional properties

1 Parte da Dissertação de Mestrado do primeiro autor, apresentada à UFCG

2 UAEA/UFCG, Av. Av. Aprígio Veloso, 882, Bairro Universitário, CEP 58429-970, Campina G rande, PB. Fone: (83) 3310-1548; 3310-1185. E-mail: tailandia10@yahoo.com.br; alex@deag.ufcg.edu.br; rossana@deag.ufcg.edu.br; tamilakassimura@yahoo.com.br; conceicaotrindade@yahoo.com.br 


\section{INTRODUÇÃO}

Estudos têm sido realizados com vistas ao aproveitamento de alimentos não convencionais, inclusive sementes de vários tipos, como as de jaca (Borges et al., 2006) e de abóbora (Glew et al., 2006); tais estudos comprovam a presença importante de fatores nutricionais como minerais, proteínas, carboidratos e fibras, na composição desses produtos.

Concentrados de minerais e vitaminas (farelos, pó de folhas, pó de sementes) em doses mínimas mas constantemente acrescidos à alimentação tradicional, fornecem nutrientes indispensáveis para promover o crescimento em crianças, aumentar a resistência a infecções e manter a saúde (DelVechio et al., 2005). Sementes de abóbora integram a composição do complemento alimentar conhecido por "multimistura", utilizado em programas assistenciais brasileiros e elaborado com a mistura de diversos ingredientes considerados subprodutos, que contêm características nutritivas similares às de tradicionais farelos de cereais. Segundo Brasil (2005), sementes de abóbora são boas fontes de proteína e gordura, na sua maior parte insaturada, vitaminas (ácido fólico, niacina) e minerais (zinco, selênio, magnésio e potássio, entre outros).

Na composição de ácidos graxos da semente de abóbora (C. moschata) o predomínio é do ácido graxo linoléico $(53,5 \%)$ (Applequist et al., 2006). De acordo com Rastogi (2004) o predomínio do ácido linoléico, por ser poliinsaturado, qualifica o óleo da semente de abóbora como benéfico à saúde, uma vez que o consumo dietético desse ácido graxo está associado à redução de doenças cardiovasculares.

A necessidade de maximizar o aproveitamento dos recursos agrícolas requer o estudo das sementes de consumo não convencional. A exploração comercial de qualquer grão ou semente alimentícia passa pelo estudo do seu armazenamento, operação fundamental para avaliar o produto nas condições de estocagem, transporte e vida de prateleira. As condições do ambiente influenciam o armazenamento; assim, o comportamento dos produtos agrícolas durante o armazenamento depende do uso de embalagens mais ou menos protetoras.

Ante esses fatos, o processamento e o armazenamento dos grãos de abóbora, destinados à alimentação se constituem em estudo básico necessário para sua exploração comercial com fins alimentícios. Esta exploração se beneficia do baixo custo da matéria-prima, considerada subproduto, e traz ganhos para toda a cadeia produtiva da abóbora.

O presente trabalho foi realizado com o objetivo de estudar as alterações químicas e físico-químicas de grãos de abóbora secos, acondicionados em embalagem rígida de polipropileno, durante o armazenamento convencional (temperatura ambiente) e testar teor de água dos grãos visando à manutenção da qualidade do produto.

\section{MATERIAL E MÉTODOS}

Os experimentos foram conduzidos no Laboratório de Armazenamento e Processamento de Produtos Agrícolas
(LAPPA) da Unidade Acadêmica de Engenharia Agrícola, da Universidade Federal de Campina Grande, PB e os grãos utilizados foram extraídos de abóboras (Cucurbita moschata Duchesne) da variedade jacarezinho, adquiridas na Empresa Paraibana de Abastecimento e Serviços Agrícolas (EMPASA) também em Campina Grande, PB. As abóboras provieram de um único produtor e se apresentavam em estádio maduro, com ligeiras variações na cor da casca.

As abóboras inteiras foram lavadas e enxaguadas em água corrente; em seguida, foram abertas e os grãos retirados, os quais foram separados da mucilagem que os envolve, lavados em água corrente, postos ao sol em bandeja de aço inoxidável para eliminação do excesso da água da lavagem e, logo após, postos em bancadas de laboratório sanitizadas, em temperatura ambiente, a fim de se remover a água remanescente da lavagem. Realizados esses procedimentos, os grãos foram misturados para uniformização do lote, embalados em sacos de polietileno de baixa densidade, contendo aproximadamente $100 \mathrm{~g}$ em cada embalagem e armazenados em freezer a $-22{ }^{\circ} \mathrm{C}$, até o momento da utilização.

Para se obter amostras com as umidades referentes a cada tratamento, grãos de abóbora congelados foram retirados do freezer, descongelados até atingir temperatura ambiente, espalhados sobre bandejas de aço inoxidável e secados em estufa com circulação forçada de ar a $100{ }^{\circ} \mathrm{C}$, até atingir o teor de água de 2, 4, 6, 8 e 10\%, aproximadamente, denominados tratamentos $\mathrm{T}_{1}, \mathrm{~T}_{2}, \mathrm{~T}_{3}, \mathrm{~T}_{4}$ e $\mathrm{T}_{5}$, respectivamente. Para se obter a umidade de cada tratamento o tempo de permanência em estufa variou conforme a umidade inicial de cada amostra.

Os grãos de abóbora do tratamento $\mathrm{T}_{1}$ com teor de água inicial de $31,6 \%$, em média, permaneciam entre 115 e 120 min na estufa; os grãos do tratamento $\mathrm{T}_{2}$, com teor de água inicial de $31,7 \%$, em média, permaneciam entre 55 e 60 min na estufa; os grãos do tratamento $\mathrm{T}_{3}$, com teor de água inicial de $31,2 \%$, em média, permaneciam entre 42 e 45 min na estufa; os grãos do tratamento $\mathrm{T}_{4}$, com teor de água inicial de $32 \%$ em média, permaneciam entre 32 e 40 min na estufa; os grãos do tratamento $\mathrm{T}_{5}$, com teor de água inicial de $31,5 \%$, em média, permaneciam entre 20 e 25 min na estufa.

Os grãos de abóbora secos, provenientes dos tratamentos, foram acondicionados em embalagens rígidas de polipropileno, com tampa não hermética e capacidade de $250 \mathrm{~mL}$ contendo, cada embalagem, cerca de $40 \mathrm{~g}$ de grãos submetidos a armazenamento em temperatura ambiente, durante 180 dias.

O cálculo do percentual de perda de água dos grãos durante as secagens foi verificado por meio da Eq. 1 (Souza Neto et al., 2004).

$$
\mathrm{P}_{\mathrm{A}}=\frac{\left(\mathrm{P}_{0} \mathrm{U}_{0}\right)-\left(\mathrm{P}_{\mathrm{t}} \mathrm{U}_{\mathrm{t}}\right)}{\mathrm{P}_{0}} 100
$$

em que:

$$
\begin{aligned}
& \mathrm{P}_{\mathrm{A}}-\text { perda percentual de água, } \% \\
& \mathrm{P}_{0}-\text { massa do produto no tempo zero, } \mathrm{g} \\
& \mathrm{P}_{\mathrm{t}}-\text { massa do produto no tempo } \mathrm{t}, \mathrm{g} \\
& \mathrm{U}_{0}-\text { teor de água do produto no tempo zero, } \\
& \quad \mathrm{g} 100^{-1} \mathrm{~g}^{-1}
\end{aligned}
$$


$\mathrm{U}_{\mathrm{t}}$ - teor de água do produto no tempo $\mathrm{t}, \mathrm{g} 100^{-1} \mathrm{~g}^{-1}$ Os grãos de abóbora secados a 2, 4, 6, 8 e $10 \%$ de teor de água, foram analisados no início (tempo zero) e a cada 30 dias de armazenamento. O teor de água, as cinzas, a proteína bruta, o pH e a acidez total titulável foram determinados conforme metodologia descrita pelo Instituto Adolfo Lutz (Brasil, 2005); o amido, segundo metodologia descrita em Lanara (Brasil, 1981); a fibra bruta, de acordo com a metodologia descrita por Ranganna (1991) e a cor foi determinada a partir de grãos triturados, em colorímetro construído conforme Motta (2005), obtendo-se os valores de L* (luminosidade), $+a^{*}$ (intensidade de vermelho) e $+b^{*}$ (intensidade de amarelo).

O teor de água final dos grãos secos para cada tratamento e em todas as embalagens, foi determinado em estufa na temperatura de $105^{\circ} \mathrm{C}$, por $24 \mathrm{~h}$, obtendo-se os resultados em termos percentuais, seguindo-se metodologia descrita pelo Instituto Adolfo Lutz (Brasil, 2005).

Os dados experimentais obtidos durante o armazenamento dos grãos de abóbora secos foram analisados estatisticamente por meio do programa computacional Assistat (Silva \& Azevedo, 2009).

O delineamento experimental utilizado foi o fatorial, com dois fatores: sete tempos de armazenamento (0, 30, 60, 90, 120, 150 e 180 dias) e cinco teor de água (2, 4, 6, 8 e 10\%), com três repetições por tratamento, com ensaios destrutivos. A comparação entre médias foi feita por meio do teste de Tukey a $5 \%$ de probabilidade.

\section{RESULTADOS E DISCUSSÃO}

\section{Teor de água}

Na Tabela 1 se apresentam os valores médios do teor de água dos grãos de abóbora secos, armazenados ao longo de 180 dias, para os cinco tratamentos. Observam-se, nesta tabela, pequenas diferenças entre os teor de água desejados para o final da secagem $(2,4,6,8$ e $10 \%)$ e o teor de água obtido de fato para o tempo zero de armazenamento $(2,76 ; 4,34$; 6,$29 ; 7,94$ e $9,21 \%$ )

Constata-se, para as amostras dos tratamentos $\mathrm{T}_{1}$ e $\mathrm{T}_{5}$, que não houve alteração significativa do teor de água com o tempo de armazenamento a $5 \%$ de probabilidade, de acordo com o teste de Tukey.

Para os grãos do tratamento $\mathrm{T}_{2}$, nota-se a manutenção do teor de água nos primeiros 90 dias de armazenamento; entre 30 e 120 dias, as médias também foram estatisticamente iguais e, a partir dos 150 dias, houve aumento significativo do teor de água em relação aos períodos anteriores, permanecendo neste nível até os 180 dias, atingindo o percentual de $37,3 \%$ entre o início e o final do armazenamento.

Para os grãos do tratamento $\mathrm{T}_{3}$ e se comparando as médias entre o tempo zero e os demais tempos, observa-se tendência de manutenção do teor de água durante o armazenamento, exceto aos 90 dias.

Analisando os resultados do tratamento $\mathrm{T}_{4}$ constata-se, entre o início e o final do armazenamento, redução significativa do teor de água com percentual de $11,96 \%$, sendo
Tabela 1. Valores médios do teor de água de grãos de abóbora acondicionados em embalagens de polipropileno e armazenados durante 180 dias

\begin{tabular}{cccllc}
\hline $\begin{array}{c}\text { Tempo de } \\
\text { armazenamento } \\
\text { (dia) }\end{array}$ & $\mathbf{T}_{\mathbf{1}}$ & $\mathbf{T}_{\mathbf{2}}$ & \multicolumn{1}{c}{$\mathbf{T}_{\mathbf{3}}$} & \multicolumn{1}{c}{$\mathbf{T}_{\mathbf{4}}$} & $\mathbf{T}_{\mathbf{5}}$ \\
0 & $2,76 \mathrm{aE}$ & $4,34 \mathrm{CD}$ & $6,29 \mathrm{bC}$ & $7,94 \mathrm{aB}$ & $9,21 \mathrm{aA}$ \\
30 & $3,10 \mathrm{aE}$ & $4,50 \mathrm{bcD}$ & $6,34 \mathrm{abC}$ & $7,18 \mathrm{bB}$ & $9,68 \mathrm{aA}$ \\
60 & $2,87 \mathrm{aE}$ & $4,67 \mathrm{bcD}$ & $6,46 \mathrm{abC}$ & $7,38 \mathrm{abB}$ & $9,28 \mathrm{aA}$ \\
90 & $2,69 \mathrm{aD}$ & $4,92 \mathrm{bcC}$ & $6,98 \mathrm{aB}$ & $7,21 \mathrm{bB}$ & $9,13 \mathrm{aA}$ \\
120 & $2,63 \mathrm{aE}$ & $5,10 \mathrm{bD}$ & $6,72 \mathrm{abC}$ & $7,56 \mathrm{abB}$ & $9,08 \mathrm{aA}$ \\
150 & $2,79 \mathrm{aD}$ & $5,84 \mathrm{aC}$ & $6,44 \mathrm{abBC}$ & $7,03 \mathrm{bB}$ & $9,39 \mathrm{aA}$ \\
180 & $2,92 \mathrm{aD}$ & $5,96 \mathrm{aC}$ & $6,64 \mathrm{abB}$ & $6,99 \mathrm{bB}$ & $9,26 \mathrm{aA}$ \\
\hline
\end{tabular}

MG $=6,21 \% ; C V=4,28 \% ;$ DMS para colunas $=0,66 ;$ DMS para linhas $=0,61$

DMS - Desvio mínimo significativo; MG - Média geral; CV - Coeficiente de variação

Obs: Médias seguidas da mesma letra minúscula nas colunas e maiúscula nas linhas, não diferem estatisticamente pelo teste de Tukey a $5 \%$ de probabilidade

maior nos primeiros 30 dias de armazenamento; a partir de 30 dias ocorre a manutenção do teor de água até o final do armazenamento.

Comparando-se as amostras dos tratamentos, verifica-se que os valores médios do teor de água nos tempos 0, 30, 60 e 120 dias de armazenamento foram estatisticamente diferentes; para os tempos de 90, 150 e 180 dias, nota-se que as médias do teor de água entre as amostras dos tratamentos $\mathrm{T}_{3}$ e $\mathrm{T}_{4}$ foram estatisticamente iguais, o mesmo ocorrendo nas amostras $T_{2}$ e $T_{3}$ aos 150 dias; nesses casos de igualdade estatística deve-se levar em conta a diferença inicial de $2 \%$, ou menos entre o teor inicial. Trocas de água das amostras com o ambiente, motivadas por variação nos tamanhos médios dos grãos ou sobreposições aleatórias dos mesmos dentro dos recipientes podem responder por diferentes absorções ou perdas de água nesta escala mas só foram observadas igualdades entre tratamentos com umidades iniciais consecutivas. Por não estarem acondicionados em embalagens herméticas, alterações no teor de água eram esperadas, uma vez que este pode variar em função da umidade relativa do ar, composição química do grão, fatores ambientais, fatores genéticos, temperatura de secagem e histerese (Chen, 2000). Segundo Marini et al. (2005) o comportamento de migração de umidade ocorre em função das condições de temperatura e umidade relativa do local de armazenamento. Pequenas imperfeições no assentamento entre a tampa e a borda da embalagem, também podem explicar diferenças na passagem de vapor às amostras. Rupollo et al. (2004) avaliaram a influência dos sistemas hermético e convencional durante doze meses de armazenamento sobre o teor de água de grãos de aveia branca (Avena sativa L.). Nos grãos armazenados pelo sistema convencional o teor de água aumentou de forma significativa, do tempo zero ao sexto mês, permanecendo estável até o final do período de armazenamento devido ao equilíbrio higroscópico.

\section{Proteína bruta}

Apresentam-se, na Tabela 2, os valores médios da proteína bruta dos grãos de abóbora secos, acondicionados em embalagens de polipropileno e armazenados durante 180 dias, para os tratamentos de variação de teor de água. 
Tabela 2. Valores médios de proteína bruta de grãos de abóbora acondicionados em embalagens de polipropileno e armazenados durante 180 dias

\begin{tabular}{ccclcc}
\hline $\begin{array}{c}\text { Tempo de } \\
\text { ammazenamento } \\
\text { (dia) }\end{array}$ & \multicolumn{5}{c}{ Proteína bruta (\%) } \\
\cline { 2 - 7 } & $\mathbf{T}_{\mathbf{1}}$ & \multicolumn{1}{c}{$\mathbf{T}_{\mathbf{2}}$} & \multicolumn{1}{c}{$\mathbf{T}_{\mathbf{3}}$} & \multicolumn{1}{c}{$\mathbf{T}_{\mathbf{4}}$} & $\mathbf{T}_{\mathbf{5}}$ \\
30 & $28,56 \mathrm{aA}$ & $27,85 \mathrm{aAB}$ & $27,32 \mathrm{bcBC}$ & $27,41 \mathrm{abBC}$ & $26,99 \mathrm{abC}$ \\
60 & $28,78 \mathrm{aA}$ & $28,16 \mathrm{aAB}$ & $27,79 \mathrm{abcBC}$ & $27,88 \mathrm{aB}$ & $27,09 \mathrm{abC}$ \\
90 & $28,75 \mathrm{aA}$ & $28,35 \mathrm{aA}$ & $28,12 \mathrm{aA}$ & $26,82 \mathrm{bB}$ & $26,88 \mathrm{abB}$ \\
120 & $28,71 \mathrm{aA}$ & $28,08 \mathrm{aAB}$ & $28,05 \mathrm{abAB}$ & $27,54 \mathrm{abB}$ & $26,60 \mathrm{bC}$ \\
150 & $28,02 \mathrm{aA}$ & $28,39 \mathrm{aAB}$ & $27,96 \mathrm{abcBC}$ & $27,37 \mathrm{abCD}$ & $26,93 \mathrm{abD}$ \\
180 & $29,93 \mathrm{aA}$ & $27,91 \mathrm{aB}$ & $27,22 \mathrm{cB}$ & $27,49 \mathrm{abB}$ & $27,40 \mathrm{aB}$ \\
\hline
\end{tabular}

MG $=27,79 \% ; C V=1,14 \% ;$ DMS para colunas $=0,79 ;$ DMS para linhas $=0,73$

DMS - Desvio mínimo significativo; MG - Média geral; CV - Coeficiente de variação

Obs: Médias seguidas da mes ma letra minúscula nas colunas e maiúscula nas linhas, não diferem estatisticamente pelo teste de Tukey a $5 \%$ de probabilidade

Constata-se, em relação ao tempo de armazenamento, que os valores médios da proteína bruta para os grãos dos tratamentos $\mathrm{T}_{1}$ e $\mathrm{T}_{2}$ foram estatisticamente iguais ao longo do período avaliado.

Observa-se, para os grãos do tratamento $\mathrm{T}_{3}$ e apesar da oscilação entre as médias, tendência de estabilidade nos valores médios da proteína bruta com o tempo de armazenamento. Para os grãos dos tratamentos $\mathrm{T}_{4} \mathrm{e} \mathrm{T}_{5}$, os valores médios da proteína bruta permaneceram sem tendência de variação durante o período. O conjunto de dados demonstra que o tempo de armazenamento não influenciou o teor de proteína bruta dos grãos de abóbora secos acondicionados em embalagens rígidas de polipropileno. Entre tratamentos, diferenças no teor de proteína bruta são observadas de forma predominante entre amostras com teor de água inicial não consecutivo, com destaque para $\mathrm{T}_{1}$ e $\mathrm{T}_{5}$, que diferiram estatisticamente em todos os tempos, com maiores valores para o tratamento $T_{1}$. Maior teor de água corresponde a menor proporção de sólidos, o que justifica menos proteína bruta no tratamento $T_{5}$. Carvalho et al. (2004) relataram que não houve efeito do tempo de armazenamento $(\mathrm{P}>0,05)$ no teor de proteína bruta do milho seco acondicionado em silos metálicos durante 180 dias, a temperatura ambiente. Souza et al. (1986) ao trabalharem com o armazenamento da farinha de castanha-do-brasil durante 120 dias, notaram aumento no teor de proteína entre o início e o final do período de estocagem.

\section{Acidez total titulável}

Na Tabela 3 estão os valores médios da acidez total titulável para os tratamentos dos grãos de abóbora secos acondicionados em embalagens de polipropileno e armazenados ao longo de 180 dias.

Em relação ao tempo de armazenamento, observou-se tendência de aumento nas médias da acidez total titulável para os cinco tratamentos, entre o início e o final do período avaliado. Este fato é devido, possivelmente, à alteração nos lipídios contidos nos grãos de abóbora, provocando a formação de ácidos graxos livres. Esta alteração lipídica pode ser definida, segundo Tiritan \& Beux (2006), como a relação entre o estado oxidativo e a estabilidade dos óleos e gorduras contidos em determinado produto, sendo que, em semen-
Tabela 3. Valores médios de acidez total titulável de grãos de abóbora acondicionados em embalagens de polipropileno e armazenados por 180 dias

\begin{tabular}{|c|c|c|c|c|c|}
\hline \multirow{2}{*}{$\begin{array}{l}\text { Tempo de } \\
\text { armazenamento } \\
\text { (dia) }\end{array}$} & \multicolumn{5}{|c|}{ Acidez total titulável (\% ácido oléico) } \\
\hline & $\mathrm{T}_{1}$ & $\mathbf{T}_{2}$ & $\mathrm{~T}_{3}$ & $\mathbf{T}_{4}$ & $\mathbf{T}_{5}$ \\
\hline 0 & $0,49 \mathrm{bA}$ & $0,27 \mathrm{bB}$ & $0,26 c B$ & 0,26 cB & $0,24 c B$ \\
\hline 30 & $0,48 \mathrm{bA}$ & $0,30 a b B$ & $0,30 \mathrm{abB}$ & $0,31 \mathrm{abB}$ & $0,28 \mathrm{bcB}$ \\
\hline 60 & $0,49 \mathrm{bA}$ & $0,29 a b B$ & $0,27 \mathrm{bcB}$ & $0,29 a b c B$ & $0,27 \mathrm{bcB}$ \\
\hline 90 & $0,49 \mathrm{bA}$ & $0,30 a b B$ & $0,27 \mathrm{bcB}$ & $0,27 \mathrm{bcB}$ & $0,29 a b B$ \\
\hline 120 & $0,55 \mathrm{aA}$ & $0,32 \mathrm{aB}$ & $0,32 \mathrm{aB}$ & $0,31 \mathrm{aB}$ & $0,30 \mathrm{abB}$ \\
\hline 150 & $0,57 \mathrm{aA}$ & $0,32 \mathrm{aB}$ & $0,32 \mathrm{aB}$ & $0,32 \mathrm{aB}$ & $0,30 a b B$ \\
\hline 180 & $0,57 \mathrm{aA}$ & $0,32 \mathrm{aB}$ & $0,32 \mathrm{aB}$ & $0,33 \mathrm{aB}$ & $0,32 \mathrm{aB}$ \\
\hline
\end{tabular}

MG $=0,34 \% ; C V=4,48 \% ;$ DMS para colunas $=0,04 ;$ DMS para linhas $=0,03$

DMS - Desvio mínimo significativo; MG - Média geral; CV - Coeficiente de variação

Obs: Médias seguidas da mes ma letra minúscula nas colunas e maiúscula nas linhas, não diferem estatisticamente pelo teste de Tukey a $5 \%$ de probabilidade

tes oleaginosas, a lipólise ocorre naturalmente. Ainda segundo esses autores, a rancidez oxidativa, também chamada auto-oxidação, é a reação do oxigênio atmosférico com as duplas ligações dos ácidos graxos insaturados. Esta provável alteração lipídica (rancidez oxidativa) pode ter sido causada pelo aquecimento dos grãos de abóbora durante a secagem e pela incidência da luz sobre os grãos durante o armazenamento, conforme Brasil (2005), a decomposição dos glicerídeos contidos nos óleos e gorduras é acelerada por aquecimento e pela luz e a rancidez é quase sempre acompanhada da formação de ácido graxo livre. Lima \& Borges (2004) ao armazenarem castanha de caju torrada em embalagem de polipropileno durante 249 dias e apesar de terem observado oscilação no índice de acidez ao longo do armazenamento, também verificaram aumento dos valores entre o início (índice de acidez $0,54 \%$ ) e o final do período avaliado (índice de acidez 1,01\%).

As médias da acidez total titulável para o tratamento $\mathrm{T}_{1}$ foram superiores às dos tratamentos $\mathrm{T}_{2}, \mathrm{~T}_{3}, \mathrm{~T}_{4} \mathrm{e} \mathrm{T}_{5}$, em todo o período avaliado, fato que se deve, provavelmente, ao maior tempo (120 min) de exposição dos grãos ao calor (temperatura de $100{ }^{\circ} \mathrm{C}$ ) em relação aos demais tratamentos.

\section{pH}

Na Tabela 4 são apresentados os valores médios do $\mathrm{pH}$ para os tratamentos dos grãos de abóbora secos acondicionados em embalagens de polipropileno, armazenados ao longo de 180 dias, a temperatura ambiente.

Tabela 4. Valores médios de pH de grãos de abóbora acondicionados em embalagens de polipropileno e armazenados por 180 dias

\begin{tabular}{|c|c|c|c|c|c|}
\hline \multirow{2}{*}{$\begin{array}{l}\text { Tempo de } \\
\text { amazenamento } \\
\text { (dia) }\end{array}$} & \multicolumn{5}{|c|}{$\mathrm{pH}$} \\
\hline & $\mathrm{T}_{1}$ & $\mathbf{T}_{2}$ & $\mathbf{T}_{3}$ & $\mathbf{T}_{4}$ & $T_{5}$ \\
\hline 0 & 5,8 & 6,2 & 6,6 & 6,6 & 6,7 \\
\hline 30 & 5,7 & 6,3 & 6,4 & 6,5 & 6,6 \\
\hline 60 & 5,6 & 6,3 & 6,3 & 6,3 & 6,4 \\
\hline 90 & 5,6 & 6,1 & 6,3 & 6,3 & 6,3 \\
\hline 120 & 5,5 & 6,1 & 6,4 & 6,4 & 6,5 \\
\hline 150 & 5,5 & 6,1 & 6,3 & 6,4 & 6,4 \\
\hline 180 & 5,5 & 6,2 & 6,3 & 6,2 & 6,2 \\
\hline
\end{tabular}


Constata-se, em relação ao tempo de armazenamento, tendência de redução nos valores do $\mathrm{pH}$ para as amostras dos tratamentos $\mathrm{T}_{1}, \mathrm{~T}_{3}, \mathrm{~T}_{4}$ e $\mathrm{T}_{5}$ entre o início e o final do armazenamento; para o tratamento $\mathrm{T}_{2}$, o $\mathrm{pH}$ se manteve estável.

Os valores médios decrescentes do $\mathrm{pH}$ correspondem aos valores médios crescentes da acidez total titulável, para todos os tratamentos, entre o início e o final do armazenamento (180 dias). Miranda \& El-Dash (2002) relataram diminuição do $\mathrm{pH}$ da farinha de trigo, durante o armazenamento, relacionada aos níveis de mudança e/ou aumento da acidez que, por sua vez, foi atribuído à deterioração por rancificação, uma vez que no processo de moagem o óleo e as enzimas presentes no germe são liberados.

\section{Cinzas}

$\mathrm{Na}$ Tabela 5 se encontram os valores médios das cinzas para os tratamentos dos grãos de abóbora secos acondicionados em embalagens de polipropileno e armazenados ao longo de 180 dias, a temperatura ambiente.

Tabela 5. Valores médios do teor de cinzas de grãos de abóbora acondicionados em embalagens de polipropileno e armazenados por 180 dias

\begin{tabular}{cccccc}
\hline $\begin{array}{c}\text { Tempo de } \\
\text { armazenamento }\end{array}$ & \multicolumn{5}{c}{ Cinzas (\%) } \\
\cline { 2 - 6 } (dia) & $\mathbf{T}_{\mathbf{1}}$ & $\mathbf{T}_{\mathbf{2}}$ & $\mathbf{T}_{\mathbf{3}}$ & $\mathbf{T}_{\mathbf{4}}$ & $\mathbf{T}_{\mathbf{5}}$ \\
0 & $3,73 \mathrm{aB}$ & $4,09 \mathrm{aA}$ & $3,95 \mathrm{aAB}$ & $4,03 \mathrm{aA}$ & $3,97 \mathrm{aAB}$ \\
30 & $3,76 \mathrm{aB}$ & $4,03 \mathrm{aA}$ & $3,88 \mathrm{aAB}$ & $3,97 \mathrm{aAB}$ & $3,96 \mathrm{aAB}$ \\
60 & $3,74 \mathrm{aC}$ & $4,15 \mathrm{aA}$ & $4,00 \mathrm{aAB}$ & $3,90 \mathrm{aABC}$ & $3,86 \mathrm{aAC}$ \\
90 & $3,75 \mathrm{aB}$ & $3,97 \mathrm{aAB}$ & $3,99 \mathrm{aAB}$ & $4,10 \mathrm{aA}$ & $3,93 \mathrm{aAB}$ \\
120 & $3,73 \mathrm{aB}$ & $3,98 \mathrm{aAB}$ & $4,01 \mathrm{aA}$ & $3,88 \mathrm{aAB}$ & $4,01 \mathrm{aA}$ \\
150 & $3,72 \mathrm{aB}$ & $4,05 \mathrm{aA}$ & $4,09 \mathrm{aA}$ & $3,89 \mathrm{aAB}$ & $4,10 \mathrm{aA}$ \\
180 & $3,73 \mathrm{aB}$ & $4,00 \mathrm{aA}$ & $3,96 \mathrm{aB}$ & $3,99 \mathrm{aAB}$ & $3,98 \mathrm{aAB}$ \\
\hline
\end{tabular}

MG $=3,94 \% ; C V=2,91 \% ;$ DMS para colunas $=0,28 ;$ DMS para linhas $=0,26$

DMS - Desvio mínimo significativo; MG - Média geral; CV - Coeficiente de variação

Obs: Médias seguidas da mesma letra minúscula nas colunas e maiúscula nas linhas, não diferem estatisticamente pelo teste de Tukey a $5 \%$ de probabilidade

Observa-se, em relação ao tempo de armazenamento, que as médias das cinzas para as amostras dos cinco tratamentos foram estatisticamente iguais em todo o período avaliado (180 dias), comportamento previsto em razão do conteúdo mineral não se alterar com o tempo de armazenamento, exceto quando existe contaminação microbiológica. Entre tratamentos, maiores teor de água devem corresponder a menores teor de cinzas, mas a metodologia empregada não permitiu tal confirmação. De acordo com Albuquerque et al. (2006), o teor de cinzas pode ser considerado medida geral de qualidade e é frequentemente utilizado como critério na identificação dos alimentos. Esses autores verificaram aumento no teor de cinzas da torta de mamona, armazenada durante seis meses, com três níveis iniciais de teor de água $(6,14$ e $22 \%$ ) e em dois tipos de embalagem (plástica e nylon), sendo o maior aumento verificado nas amostras armazenadas em embalagem de nylon. Este tipo de embalagem mantinha o produto com maior contato com o meio, facilitando a incidência de micro-organismos deteriorantes, disponibilizando os nutrientes minerais existen- tes no produto. Donadel \& Prudencio-Ferreira (1999) ao armazenarem, durante 40 dias, farinha de feijão da variedade carioca, constataram que não houve variação estatística no percentual médio das cinzas, ao longo do armazenamento.

\section{Fibra bruta}

Tem-se, na Tabela 6, os valores médios da fibra bruta para os tratamentos dos grãos de abóbora secos acondicionados em embalagens de polipropileno e armazenados ao longo de 180 dias, a temperatura ambiente.

Tabela 6. Valores médios do teor de fibra bruta de grãos de abóbora acondicionados em embalagens de polipropileno e armazenados por 180 dias

\begin{tabular}{cccccc}
\hline $\begin{array}{c}\text { Tempo de } \\
\text { amazenamento } \\
\text { (dia) }\end{array}$ & $\mathbf{T}_{\mathbf{1}}$ & $\mathbf{T}_{\mathbf{2}}$ & $\mathbf{T}_{\mathbf{3}}$ & $\mathbf{T}_{\mathbf{4}}$ & $\mathbf{T}_{\mathbf{5}}$ \\
0 & $46,13 \mathrm{aA}$ & $45,15 \mathrm{aA}$ & $44,65 \mathrm{aA}$ & $44,97 \mathrm{aA}$ & $44,79 \mathrm{aA}$ \\
30 & $45,74 \mathrm{aA}$ & $44,90 \mathrm{aA}$ & $44,60 \mathrm{aA}$ & $44,31 \mathrm{aA}$ & $44,48 \mathrm{aA}$ \\
60 & $45,85 \mathrm{aA}$ & $45,16 \mathrm{aA}$ & $45,34 \mathrm{aA}$ & $44,70 \mathrm{aA}$ & $44,61 \mathrm{aA}$ \\
90 & $45,94 \mathrm{aA}$ & $44,97 \mathrm{aA}$ & $44,99 \mathrm{aA}$ & $44,88 \mathrm{aA}$ & $45,18 \mathrm{aA}$ \\
120 & $46,00 \mathrm{aA}$ & $45,32 \mathrm{aA}$ & $44,61 \mathrm{aA}$ & $45,33 \mathrm{aA}$ & $44,72 \mathrm{aA}$ \\
150 & $46,19 \mathrm{aA}$ & $45,19 \mathrm{aA}$ & $45,11 \mathrm{aA}$ & $45,15 \mathrm{aA}$ & $44,75 \mathrm{aA}$ \\
180 & $45,64 \mathrm{aA}$ & $45,41 \mathrm{aA}$ & $45,04 \mathrm{aA}$ & $45,43 \mathrm{aA}$ & $44,81 \mathrm{aA}$ \\
\hline
\end{tabular}

MG $=45,14 \% ; C V=2,14 \% ;$ DMS para colunas $=2,32 ;$ DMS para linhas $=2,14$

DMS - Desvio mínimo significativo; MG - Média geral; CV - Coeficiente de variação

Obs.: Médias seguidas da mesma letra minús cula nas colunas e maiúscula nas linhas, não diferem estatisticamente pelo teste de Tukey a $5 \%$ de probabilidade

Observa-se, em relação ao tempo de armazenamento, que as médias da fibra bruta para as amostras dos cinco tratamentos não apresentaram variação estatística em todo o período avaliado (180 dias). Marcílio et al. (2003), ao determinarem o teor de fibra da farinha integral do grão de amaranto (Amaranthus cruentus) brasileiro com dois teor de água, 9,2 e 13,7\%, também não notaram variação entre os valores médios obtidos. D’Agostini et al. (2004) determinaram o teor de fibra em amostras de grãos de milho in natura e grãos de milho precozidos e verificaram que o cozimento não ocasionou alteração no percentual de fibra, entre as amostras.

\section{Amido}

Na Tabela 7 se acha o teor médio de amido para os tratamentos dos grãos de abóbora secos acondicionados em embalagens de polipropileno e armazenados ao longo de 180 dias, em temperatura ambiente.

Verifica-se, em relação ao tempo de armazenamento, que as médias de teor de amido, para os grãos dos tratamentos foram estatisticamente iguais entre o início (tempo zero) e o final do período avaliado (180 dias). Entre tratamentos, confirma-se a expectativa de maior teor de amido nas amostras com menor teor de água, embora entre $\mathrm{T}_{3}$ e $\mathrm{T}_{4}$ as diferenças não se verifiquem em todos os tempos. Feitosa (2007) observou que as amêndoas de jaca secas, com e sem película, mantiveram o teor de amido inalterado no período de 180 dias de armazenamento. 
Tabela 7. Valores médios do teor de amido de grãos de abóbora acondicionados em embalagens de polipropileno e armazenados por 180 dias

\begin{tabular}{cccccc}
\hline $\begin{array}{c}\text { Tempo de } \\
\text { armazenamento } \\
\text { (dia) }\end{array}$ & $\mathbf{T}_{\mathbf{1}}$ & $\mathbf{T}_{\mathbf{2}}$ & \multicolumn{1}{c}{$\mathbf{T}_{\mathbf{3}}$} & $\mathbf{T}_{\mathbf{4}}$ & $\mathbf{T}_{\mathbf{5}}$ \\
0 & $7,94 \mathrm{aA}$ & $6,49 \mathrm{aB}$ & $6,30 \mathrm{aB}$ & $5,40 \mathrm{abC}$ & $5,23 \mathrm{aC}$ \\
30 & $7,66 \mathrm{aA}$ & $6,21 \mathrm{aB}$ & $5,89 \mathrm{abB}$ & $5,21 \mathrm{bC}$ & $5,14 \mathrm{aC}$ \\
60 & $7,51 \mathrm{aA}$ & $6,30 \mathrm{aB}$ & $5,66 \mathrm{bC}$ & $5,73 \mathrm{abC}$ & $5,52 \mathrm{aC}$ \\
90 & $7,53 \mathrm{aA}$ & $6,13 \mathrm{aB}$ & $5,81 \mathrm{abBC}$ & $5,66 \mathrm{abBC}$ & $5,46 \mathrm{aC}$ \\
120 & $7,79 \mathrm{aA}$ & $6,40 \mathrm{aB}$ & $5,52 \mathrm{bC}$ & $5,59 \mathrm{abC}$ & $5,39 \mathrm{aC}$ \\
150 & $7,92 \mathrm{aA}$ & $6,38 \mathrm{aB}$ & $5,81 \mathrm{bC}$ & $5,80 \mathrm{aC}$ & $5,66 \mathrm{aC}$ \\
180 & $7,95 \mathrm{aA}$ & $6,04 \mathrm{aB}$ & $6,04 \mathrm{abB}$ & $5,52 \mathrm{abBC}$ & $5,36 \mathrm{aC}$ \\
\hline
\end{tabular}

MG $=6,16 \% ; C V=3,73 \% ;$ DMS para colunas $=0,57 ;$ DMS para linhas $=0,53$

DMS - Desvio mínimo significativo; MG - Média geral; CV - Coeficiente de variação

Obs: Médias seguidas da mesma letra minúscula nas colunas e maiúscula nas linhas, não diferem estatisticamente pelo teste de Tukey a $5 \%$ de probabilidade

\section{Luminosidade}

$\mathrm{Na}$ Tabela 8 encontram os valores médios da luminosidade para os tratamentos dos grãos de abóbora secos acondicionados em embalagens de polipropileno e armazenados ao longo de 180 dias, a temperatura ambiente.

Tabela 8. Valores médios de luminosidade de grãos de abóbora acondicionados em embalagens de polipropileno e armazenados por 180 dias

\begin{tabular}{cccccc}
\hline $\begin{array}{c}\text { Tempo de } \\
\text { armazenamento }\end{array}$ & \multicolumn{5}{c}{ Luminosidade (L*) } \\
\cline { 2 - 6 } (dia) & $\mathbf{T}_{\mathbf{1}}$ & $\mathbf{T}_{\mathbf{2}}$ & $\mathbf{T}_{\mathbf{3}}$ & $\mathbf{T}_{\mathbf{4}}$ & $\mathbf{T}_{\mathbf{5}}$ \\
0 & $48,83 \mathrm{bC}$ & $50,93 \mathrm{aB}$ & $53,22 \mathrm{aA}$ & $52,89 \mathrm{aA}$ & $53,26 \mathrm{aA}$ \\
30 & $49,05 \mathrm{bC}$ & $51,19 \mathrm{aB}$ & $52,88 \mathrm{aA}$ & $52,88 \mathrm{aA}$ & $53,23 \mathrm{aA}$ \\
60 & $48,92 \mathrm{bC}$ & $51,05 \mathrm{aB}$ & $52,88 \mathrm{aA}$ & $52,84 \mathrm{aA}$ & $53,16 \mathrm{aA}$ \\
90 & $49,79 \mathrm{abC}$ & $50,86 \mathrm{aB}$ & $52,98 \mathrm{aA}$ & $53,00 \mathrm{aA}$ & $52,98 \mathrm{aA}$ \\
120 & $48,75 \mathrm{bC}$ & $50,77 \mathrm{aB}$ & $53,24 \mathrm{aA}$ & $52,93 \mathrm{aA}$ & $53,18 \mathrm{aA}$ \\
150 & $48,82 \mathrm{bC}$ & $51,08 \mathrm{aB}$ & $52,92 \mathrm{aA}$ & $52,87 \mathrm{aA}$ & $53,15 \mathrm{aA}$ \\
180 & $48,65 \mathrm{bC}$ & $50,91 \mathrm{aB}$ & $52,85 \mathrm{aA}$ & $52,82 \mathrm{aA}$ & $53,09 \mathrm{aA}$ \\
\hline
\end{tabular}

MG $=51,79 ; \mathrm{CV}=0,36 \% ;$ DMS para colunas $=0,47:$ DMS para linhas $=0,43$

DMS - Desvio mínimo significativo; MG - Média geral; CV - Coeficiente de variação

Obs: Médias seguidas da mesma letra minúscula nas colunas e maiúscula nas linhas, não diferem estatisticamente pelo teste de Tukey a $5 \%$ de probabilidade

Em relação ao tempo de armazenamento, constata-se que as médias da luminosidade para as amostras dos cinco tratamentos foram estatisticamente iguais em todo o período avaliado (180 dias). A manutenção da luminosidade dos grãos de abóbora secos durante o armazenamento demonstra estabilidade neste parâmetro nos teor de água e no tempo avaliado. Afonso Júnior \& Corrêa (2003) constataram que não houve alteração na luminosidade dos grãos de café com casca da variedade Catuaí preprocessados por via seca, acondicionados em sacos de papel e armazenados durante 12 meses sob condições ambientais de laboratório quanto a temperatura e umidade relativa. Esses pesquisadores sugeriram que a casca que reveste o grão contribuiu para sua proteção, reduzindo os prováveis efeitos ambientais sobre a luminosidade do produto armazenado.

Constata-se, em relação aos tratamentos, que as médias da luminosidade dos grãos do tratamento $T_{1}$ foram menores que as dos demais tratamentos e as médias da luminosidade dos grãos do tratamento $\mathrm{T}_{2}$ são menores que as dos grãos dos tratamentos $\mathrm{T}_{3}, \mathrm{~T}_{4}$ e $\mathrm{T}_{5}$, para todos os tempos de armazenamento. Este resultado pode ser atribuído ao fato dos grãos do tratamento $T_{1}$ haverem passado maior tempo expostos ao calor, entre 115 e 120 min, seguidos dos grãos do tratamento $\mathrm{T}_{2}$, entre 55 e $60 \mathrm{~min}$. As médias da luminosidade dos grãos dos tratamentos $\mathrm{T}_{3}, \mathrm{~T}_{4}$ e $\mathrm{T}_{5}$, foram estatisticamente iguais para todos os tempos de armazenamento, o que pode ser explicado em virtude dos grãos dos tratamentos $\mathrm{T}_{3}$, $\mathrm{T}_{4}$ e $\mathrm{T}_{5}$ terem passado os menores tempos expostos ao calor, entre 20 e $45 \mathrm{~min}$. Conforme Shin \& Bhowmik (1995) a mudança de cor do alimento está associada ao tratamento térmico; a retenção de cor após o tratamento térmico pode ser usada para prever a extensão da deterioração qualitativa resultante da exposição do alimento ao calor.

\section{Intensidade de vermelho}

$\mathrm{Na}$ Tabela 9 estão os valores médios da intensidade de vermelho para os tratamentos dos grãos de abóbora secos acondicionados em embalagens de polipropileno e armazenados ao longo de 180 dias, a temperatura ambiente.

Tabela 9. Valores médios de intensidade de vermelho de grãos de abóbora acondicionados em embalagens de polipropileno e armazenados por 180 dias

\begin{tabular}{cccccc}
\hline \multirow{2}{*}{$\begin{array}{c}\text { Tempo de } \\
\text { amazenamento } \\
\text { (dia) }\end{array}$} & $\mathbf{T}_{\mathbf{1}}$ & $\mathbf{T}_{\mathbf{2}}$ & $\mathbf{T}_{\mathbf{3}}$ & $\mathbf{T}_{\mathbf{4}}$ & $\mathbf{T}_{\mathbf{5}}$ \\
\cline { 2 - 7 } & $12,79 \mathrm{abA}$ & $9,95 \mathrm{bB}$ & $8,09 \mathrm{aC}$ & $8,16 \mathrm{aC}$ & $8,00 \mathrm{aC}$ \\
30 & $12,99 \mathrm{abA}$ & $10,06 \mathrm{bB}$ & $8,95 \mathrm{aBC}$ & $8,29 \mathrm{aC}$ & $8,16 \mathrm{aC}$ \\
60 & $13,89 \mathrm{aA}$ & $9,71 \mathrm{bB}$ & $8,13 \mathrm{aC}$ & $8,06 \mathrm{aC}$ & $7,87 \mathrm{aC}$ \\
90 & $11,54 \mathrm{bA}$ & $11,64 \mathrm{aA}$ & $8,27 \mathrm{aB}$ & $8,42 \mathrm{aB}$ & $8,34 \mathrm{aB}$ \\
120 & $12,97 \mathrm{abA}$ & $10,46 \mathrm{abB}$ & $7,93 \mathrm{aC}$ & $8,11 \mathrm{aC}$ & $8,17 \mathrm{aC}$ \\
150 & $13,35 \mathrm{aA}$ & $10,44 \mathrm{abB}$ & $8,73 \mathrm{aC}$ & $8,25 \mathrm{aC}$ & $8,13 \mathrm{aC}$ \\
180 & $14,06 \mathrm{aA}$ & $9,99 \mathrm{bB}$ & $8,06 \mathrm{aC}$ & $8,09 \mathrm{aC}$ & $7,89 \mathrm{aC}$ \\
\hline
\end{tabular}

MG $=9,59 ; \mathrm{CV}=6,25 \% ;$ DMS para colunas $=1,49 ;$ DMS para linhas $=1,37$

DMS - Desvio mínimo significativo; MG - Média geral; CV - Coeficiente de variação

Obs: Médias seguidas da mesma letra minúscula nas colunas e maiúscula nas linhas, não diferem estatisticamente pelo teste de Tukey a $5 \%$ de probabilidade

Verifica-se, em relação ao tempo de armazenamento, tendência de manutenção nas médias da intensidade de vermelho para os grãos dos tratamentos $\mathrm{T}_{1}$ e $\mathrm{T}_{2}$, apesar de existir diferença significativa entre médias; para os grãos dos tratamentos $\mathrm{T}_{3}, \mathrm{~T}_{4}$ e $\mathrm{T}_{5}$ não há variação estatística em todo o período avaliado. Entre tratamentos, observa-se predomínio de valores maiores nos tratamentos $\mathrm{T}_{1}$ e $\mathrm{T}_{2}$. Como nesses tratamentos as amostras permaneceram mais tempo em estufa pode-se atribuir a isto a diferença na intensidade de vermelho, que se manifestou desde o tempo zero. De modo geral, a intensidade de vermelho segue a mesma tendência da luminosidade dos grãos de abóbora secos. Lima et al. (2008) também verificaram que não houve variação estatística nas médias da intensidade de vermelho de grãos de milho e do farelo de soja acondicionados em armazém, a temperatura ambiente, com teor de água inicial de 10,86 e $12,70 \%$, respectivamente, durante 28 dias de armazenamento. 


\section{Intensidade de amarelo}

Na Tabela 10 se encontram os valores médios da intensidade de amarelo $\left(+b^{*}\right)$ para os tratamentos dos grãos de abóbora secos acondicionados em embalagens de polipropileno e armazenados ao longo de 180 dias, a temperatura ambiente.

Tabela 10. Valores médios de intensidade de amarelo de grãos de abóbora acondicionados em embalagens de polipropileno e armazenados por 180 dias

\begin{tabular}{cccccc}
\hline $\begin{array}{c}\text { Tempo de } \\
\text { armazenamento } \\
\text { (dia) }\end{array}$ & $\mathbf{T}_{\mathbf{1}}$ & $\mathbf{T}_{\mathbf{2}}$ & $\mathbf{T}_{\mathbf{3}}$ & $\mathbf{T}_{\mathbf{4}}$ & $\mathbf{T}_{\mathbf{5}}$ \\
\cline { 2 - 6 } & $15,49 \mathrm{abA}$ & $12,36 \mathrm{aB}$ & $10,91 \mathrm{aC}$ & $10,79 \mathrm{aC}$ & $10,37 \mathrm{aC}$ \\
30 & $15,53 \mathrm{abA}$ & $12,96 \mathrm{aB}$ & $11,15 \mathrm{aC}$ & $11,12 \mathrm{aC}$ & $11,08 \mathrm{aC}$ \\
60 & $14,81 \mathrm{bA}$ & $12,55 \mathrm{aB}$ & $10,64 \mathrm{aC}$ & $10,57 \mathrm{aC}$ & $10,61 \mathrm{aC}$ \\
90 & $16,24 \mathrm{aA}$ & $12,19 \mathrm{aB}$ & $10,80 \mathrm{aC}$ & $10,78 \mathrm{aC}$ & $10,81 \mathrm{aC}$ \\
120 & $14,99 \mathrm{bA}$ & $12,48 \mathrm{aB}$ & $11,04 \mathrm{aC}$ & $10,71 \mathrm{aC}$ & $10,51 \mathrm{aC}$ \\
150 & $14,82 \mathrm{bA}$ & $12,47 \mathrm{aB}$ & $11,51 \mathrm{aC}$ & $11,09 \mathrm{aC}$ & $11,21 \mathrm{aC}$ \\
180 & $14,64 \mathrm{bA}$ & $12,57 \mathrm{aB}$ & $10,69 \mathrm{aC}$ & $10,54 \mathrm{aC}$ & $10,85 \mathrm{aC}$ \\
\hline
\end{tabular}

$M G=12,05 ; C V=3,39 \% ;$ DMS para colunas $=1,01 ;$ DMS para linhas $=0,94$

DMS - Desvio mínimo significativo; MG - Média geral; CV - Coeficiente de variação

Obs: Médias seguidas da mes ma letra minúscula nas colunas e maiúscula nas linhas, não diferem estatisticamente pelo teste de Tukey a $5 \%$ de probabilidade

Constata-se tendência de manutenção em relação ao tempo de armazenamento das médias da intensidade de amarelo para os grãos do tratamento $\mathrm{T}_{1}$; para os grãos dos tratamentos $\mathrm{T}_{2}, \mathrm{~T}_{3}, \mathrm{~T}_{4}$ e $\mathrm{T}_{5}$, observa-se que não houve diferença estatística em todo o período avaliado (180 dias). De modo geral, a intensidade de amarelo segue a mesma tendência da luminosidade e da intensidade de vermelho dos grãos de abóbora secos. A manutenção da intensidade de amarelo durante o armazenamento demonstra a estabilidade deste parâmetro nas condições estudadas. De forma idêntica à observada na intensidade de vermelho, os maiores valores na intensidade de amarelo estão presentes nos tratamentos $\mathrm{T}_{1}$ e $\mathrm{T}_{2}$ devido, provavelmente, ao mesmo motivo, ou seja, à permanência mais prolongada em estufa das amostras referentes a esses tratamentos. Gutkoski et al. (2007) constataram que a farinha de trigo acondicionada em sacos de polietileno de baixa densidade a temperatura ambiente, tornou-se mais clara, isto é, os valores de luminosidade aumentaram significativamente $(\mathrm{p}<0,01)$ com o aumento do tempo de armazenamento, porém os valores de intensidade de amarelo foram reduzidos significativamente com o tempo de armazenamento. Esses pesquisadores atribuíram as alterações ao processo de maturação da farinha com o aumento do tempo de armazenamento. A maturação da farinha ocorre a partir da oxidação das proteínas do glúten e dos pigmentos carotenóides.

\section{CONCLUSÕES}

1. Os grãos de abóbora com teor de água entre 2 e $10 \%$, armazenados em embalagens de polipropileno não herméticas, mantiveram a maioria das suas características químicas e nutricionais inalteradas durante 180 dias.
2. Durante o armazenamento dos grãos secos a acidez total titulável apresentou tendência de aumento com o tempo; o pH mostrou tendência de redução; o teor de proteína, cinzas, fibra e amido, assim como a luminosidade, a intensidade de vermelho e a intensidade de amarelo, se mantiveram inalterados.

3. O teor de água inicial na faixa estudada não afetou a manutenção da qualidade das amostras ao longo do armazenamento.

\section{AGRADECIMENTO}

Ao CNPQ, pela concessão de bolsa de Mestrado.

\section{LITERATURA CITADA}

Afonso Júnior, P. C.; Corrêa, P. C. Influência do tempo de armazenagem na cor dos grãos de café pré-processados por "via seca" e "via úmida". Ciência e Agrotecnologia, v.27, n.6, p.1268-1276, 2003.

Albuquerque, R. C.; Sampaio, L. R.; Ribeiro, R. R. F. Beltrão, N. E. de M.; Severino, L. S.; Freire, R. M. M.; Pedroza, J. P. Teor de cinzas e matéria orgânica da torta de mamona em função do armazenamento em diferentes embalagens. In: Congresso Brasileiro de Mamona, 2, 2006, Campina Grande. Anais... Campina Grande: EMBRAPA, 2006. CD-Rom

Applequist, W. L.; Brian, B. A.; Schaneberg, T.; Wang, Y. H.; Khan, I. A. Comparative fatty acid content of seeds of four Cucurbita species grown in a common (shared) garden. Journal of Food Composition and Analysis, v.19, n.6, p.606-611, 2006.

Borges, S. V.; Bonilha, C. C.; Mancini, M. C. Sementes de jaca (Artocapus integrifolia) e de abóbora (Cucurbita moschata) desidratadas em diferentes temperaturas e utilizadas como ingredientes em biscoitos tipo cookie. Alimentação e Nutrição, v.17, n.3, p.317-321, 2006.

Brasil. Ministério da Agricultura. Laboratório Nacional de Referência Animal (LANARA). Métodos analíticos oficiais para controle de produtos de origem animal e seus ingredientes: II métodos físicos e químicos. Brasília: Ministério da Agricultura, 1981. v.2. 188 p.

Brasil. Ministério da Saúde. Agência Nacional de Vigilância Sanitária. Métodos físico-químicos para análise de alimentos. Brasília: Ministério da Saúde, 2005. 1017p.

Carvalho, D. C. O.; Albino, L. F. T.; Rostagno, H. S.; Oliveira, J. E.; Vargas Júnior, J. G.; Toledo, R. S.; Costa, C. H. R.; Pinheiro, S. R. F.; Souza, R. M. Composição química e energética de amostras de milho submetidas a diferentes temperaturas de secagem e períodos de armazenamento. Revista Brasileira de Zootecnia, v.33, n.2, p.358-364, 2004.

Chen, C. A rapid method to determine the sorption isotherms of peanuts. Journal Agricultural Engineering Research, v.75, n.4, p.401-408, 2000.

D’Agostini, P.; Gomes, P. C.; Albino, L. F. T. Valores de composição química e energética de alguns alimentos para aves. Revista Brasileira de Zootecnia, v.33, n.1, p.128-134, 2004. 
Del-Vechio, G.; Corrêa, A. D.; Abreu, P. C. M; Santos, C. D. Efeito do tratamento térmico em sementes de abóboras (Cucurbita spp.) sobre os níveis de fatores antinutricionais e/ou tóxicos. Ciência e Agrotecnologia, v.29, n.2, p.369-376, 2005.

Donadel, M. E.; Prudencio-Ferreira, S. H. Propriedades funcionais de concentrado protéico de feijão envelhecido. Ciência e Tecnologia de Alimentos, v.19, n.3, p.380-386, 1999.

Feitosa, R. M. Processamento e armazenamento das amêndoas de jaca. Campina Grande: UFCG, 2007. 92p. Dissertação Mestrado

Glew, R. H.; Glew, R.S.; Chuang, L. T.; Huang, Y. S.; Millson, M.; Constans, D.; Vanderjagt, D. J. Amino acid, mineral and fatty acid content of pumpkin seeds (Cucurbita spp) and Cyperus esculentus nuts in the republic of Niger. Plant Foods for Human Nutrition, v.61, n.2, p.51-56, 2006.

Gutkoski, L. C.; Klein, B.; Kaster, B.; Gonçalves, F. T.; Lamaison, F. C.; Spier. F.; Friedrich, M. T. Armazenamento da farinha de trigo enriquecida com ferro e ácido fólico e seu efeito na produção de pão de forma. Alimentos e Nutrição, v.18, n.1, p.93-100, 2007.

Lima, I. F.; Alves, A. F.; Ramos, Z. N. S.; Andrade, L. F.; Apolinário, J. R.; Silva, J. H. V. Avaliação físico-química de grãos de milho e farelo de soja em diferentes tempos de armazenamento. In: Jornada Nacional da Agroindústria, 3, 2008, Bananeiras. Anais... Bananeiras: UFPB, 2008. CD-Rom.

Lima, J. R.; Borges, M. F. Armazenamento de amêndoas de castanha de caju: Influência da embalagem e da salga. Revista Ciência Agronômica, v.35, n.1, p.104-109, 2004.

Marcílio, R.; Amaya-Farfan, J.; Silva, M. A. A. P. Fracionamento do grão de amaranto (A. cruentus) brasileiro e suas características composicionais. Ciência e Tecnologia de Alimentos, v.23, n.3, p.511-516, 2003.
Marini, L. J.; Gutkoski, L. C.; Elias, M. C.; Mezzomo, N. Efeito da secagem intermitente na estabilidade de grãos de aveia. Brazilian Journal of Food Technology, v.8, n.3, p.260-267, 2005.

Miranda, M. Z.; El-Dash, A. Farinha integral de trigo germinado: características nutricionais e estabilidade ao armazenamento. Ciência e Tecnologia de Alimentos, v.22, n.3, p.216-223, 2002.

Motta, J. D. Construção e avaliação de um colorímetro para produtos agrícolas. Campina Grande: UFCG, 2005. 91p. Dissertação Mestrado

Ranganna, S. Analysis and quality control for fruit and vegetable products. New Delhi: McGraw-Hill, 1991. 1112p.

Rastogi, T. Diet and risk of ischemic heart disease in India. American Journal of Clinical Nutrition, v.79, n.10, p.92-582, 2004.

Rupollo, G.; Gutkoski, L. C.; Marini, L. J.; Elias, M. C. Sistemas de armazenamentos hermético e convencional na conservabilidade de grãos de aveia. Ciência Rural, v.34, n.6, p.1715-1722, 2004.

Shin, S.; Bhowmik, S. R. Thermal kinetics of color changes in pea puree. Journal of Food Engineering, v.24, n.1, p.77-86, 1995.

Silva, F. de A.S. e; Azevedo, C. A. V. de. Principal components analysis in the software Assistat-Statistical Attendance. In: World Congress on Computers in Agriculture, 7, Reno. Anais... Reno: American Society of Agricultural and Biological Engineers, 2009.

Souza, M. L.; Holanda, L. F. F.; Maia, G. A.; Gaspar Júnior, J. C.; Figueiredo, R. W. Estudo do processamento e estabilidade da farinha de amêndoa da castanha-do-Brasil. Ciência Agrônomica, v.17, n.1, p.35-42, 1986.

Souza Neto, M. A.; Maia, G. A.; Lima, J. R.; Figueiredo, R. W.; Souza Filho, M. de S. M.; Lima, A. S. Cinética de desidratação osmótica de manga. Ciências Agrárias e Engenharias, v.10, n.2, p.37-44, 2004.

Tiritan, M. G.; Beux, S. Controle da qualidade do óleo de soja degomado. Synergismus Scyentifica, v.1, n.2, p.306-316, 2006. 